Invited Feature Article

\title{
Photoluminescence of CdSe and CdSe/ZnS Quantum Dots: Modifications for Making the Invisible Visible at Ensemble and Single-molecule Levels
}

\author{
Edakkattuparambil S. Shibu, ${ }^{1}$ Morohiko Hamada, ${ }^{1,2}$ Shunsuke Nakanishi, ${ }^{2}$ Shin-ichi Wakida, ${ }^{1}$ \\ Vasudevanpillai Biju ${ }^{* 1,3}$ \\ ${ }^{1}$ Health Research Institute, National Institute of Advanced Industrial Science and Technology (AIST), \\ Takamatsu, Kagawa 761-0395, Japan \\ ${ }^{2}$ Department of Advanced Materials Science, Kagawa University, Takamatsu, Kagawa, Japan \\ ${ }^{3}$ PRESTO, Japan Science and Technology Agency, Tokyo 332-0012, Japan \\ E-mail:v.biju@aist.go.jp
}

\begin{abstract}
This thematic article is written with an intention to provide an overview of our recent research on the modulation of quantum dots photoluminescence and the applications of quantum dots to bioimaging. In particular, we summarize the physiochemical factors that affect the photoluminescence of $\mathrm{CdSe}$ or $\mathrm{CdSe} / \mathrm{ZnS}$ quantum dots at ensemble and single-molecule levels, blinking and blinking suppression of quantum dots, bioconjugation of quantum dots, applications of bioconjugated quantum dots for analyzing some selected biophysical processes at single-molecule levels, and intracellular delivery of quantum dot bioconjugates. These research subjects are correlated with the state of the art accomplishments in the quantum dot field.
\end{abstract}

Keywords: Quantum dots, photoluminescence, energy transfer, electron transfer, singlemolecule, blinking, FRET, biolabeling, bioimaging

\section{Introduction}

The large surface to volume ratios and the molecule-like electronic band structures that emerge from the strong quantum confinement of charge carriers are fundamental to the unique size- and shape- dependent tunable optical and electronic properties of nanomaterials. Bottom-up syntheses of nanomaterials with uniform -size, -shape and -composition, and the unique optical and electronic properties have not only brought revolutionary developments in the nanoscience and nanotechnology areas but also strengthened the cross-disciplinary research at interfaces among chemistry, physics, biology, and engineering and medical sciences. Nanomaterials of semiconductors, metals and carbon have brought to us highly efficient and miniaturized photovoltaic, electro-optic and optoelectronic devices. At the same

(C) 2013. This manuscript version is made available under the Elsevier user license 
time, gold nanoparticles (NPs) [1-4], semiconductor quantum dots (QDs) [5-8], upconversion NPs [9-11] and carbon nanotubes [12-14] have received considerable attention in modern bioimaging and therapeutic interventions owing to their unique optical properties, solubility and stability in physiological ambiance, flexible surface chemistry, and excellent biocompatibility $[15,16]$. Among these nanomaterials, cadmium chalcogenide QDs, owing to their size-dependent tunable absorption and emission bands and exceptionally bright and stable photoluminescence, are of particular recent interest in the construction of excellent electro-optical devices and displays, and the imaging of biomolecules, cells and tissues.

QDs are semiconductor nanoparticles in which electrons and holes are three dimensionally confined within the exciton Bohr radius of the material. In the past two decades, QDs received considerable attention in different aspects of chemistry, physics and biology owing to their broad absorption and narrow emission bands, large molar extinction coefficient, high photoluminescence quantum yield, and exceptional photostability[5-8,17]. Since Louis Brus has derived the relation between size and electronic band gap in semiconductor nanocrystals in 1984 by applying the particle in a sphere model approximation to the bulk Wannier Hamiltonian [18], it took nearly a decade for the systematic experimental validation of the relation between size and band gap, when Bawendi and coworkers realized the colloidal synthesis and size-selective precipitation of $\mathrm{CdX}$ QDs ( $\mathrm{X}=\mathrm{S}, \mathrm{Se}, \mathrm{Te})$ [19]. Soon after this report, Weller and coworkers synthesized $\mathrm{CdS}$ QDs using $\mathrm{CdClO}_{4}$ in place of volatile $\mathrm{CdMe}_{2}[20]$. However, the applications of $\mathrm{CdX}$ QDs prepared by these methods were limited due to their poor photoluminescence quantum efficiency, chemical instability, toxicity, poor solubility in the aqueous phase, and unresolved surface chemistry. Most of these limitations were resolved with the preparation of $\mathrm{ZnS}$ shell on $\mathrm{CdX}$ core, which involves the pyrolysis of a mixture of diethyl zinc and hexamethyldisilathiane [21,22]. Nevertheless, random telegraphic signaling, also called blinking photoluminescence, identified in 1996 $[23,24]$, continues to be an undesired disorder that limits certain applications of QDs, such as single molecule detections and on-demand single photon emission. A clear picture of the band structure in CdSe QDs has become available with the rationalization of electronic fine structures associated with the asymmetric splitting of hole states, and electron-hole exchange perturbations $[25,26]$. Along with the advancements in the physics of QDs, the potentials of CdSe QDs as highly photostable fluorescent tags for bioimaging were realized with the introduction of biocompatible QDs for cell labeling by Alivisatos and coworkers [27] and Nie and coworkers [28]. 
Many years after these early developments, Peng and coworkers reported the synthesis of monodisperse and shape- and size- controlled QDs, in which the volatile $\mathrm{CdMe}_{2}$ is replaced with greener precursors such as cadmium oxide, cadmium acetate or cadmium carbonate $[29,30]$. With the introduction of these greener precursors, synthesis and applications of QDs have become straightforward. QDs synthesized by the above methods do not have any intrinsic solubility in water, which guided into alternative methods for the synthesis of sizecontrolled QDs in the aqueous phase [31-33]. In parallel, aqueous conversion of QDs capped with hydrophobic ligands is extensively investigated [28,34-48]. Such ligand exchange reactions on the surface of QDs not only enable the dispersion of QDs in the aqueous phase but also offer surface functional groups for bioconjugation and cell labeling [5-8,15,16,49]. Among various chalcogenide QDs investigated so far, $\mathrm{CdSe} / \mathrm{ZnS}$ finds special interest in areas such as electro-optical and photovoltaic technology and bioimaging owing to their bright, stable and size-dependent tunable photoluminescence in the visible region. In this article, we summarize how the local -physical and -chemical environments modulate the ensemble photoluminescence properties and single-molecule blinking of $\mathrm{CdSe}$ and $\mathrm{CdSe} / \mathrm{ZnS}$ QDs. Also, we highlight on the predation of QD-bioconjugates and their applications for the detection or imaging of cells and biomolecules. Literature reports about optical properties and bioimaging applications of $\mathrm{CdSe}$ or $\mathrm{CdSe} / \mathrm{ZnS}$ QDs are precisely reviewed under individual subtitles in this review article. Regarding to our own research, we first show thermal modulation of QD photoluminescence. Successively, we recruit polar molecules, polymers, titanium dioxide nanoparticles or fullerenes to the surface of CdSe or CdSe/ZnS QDs and analyze how such molecular or nanomaterial environment modifies the defects or carrierrelaxation process in QDs. Further, we move on to the bioconjugation of CdSe/ZnS QDs and the analysis of the potentials of bioconjugated QDs to literally light up certain biochemical and biophysical processes such as DNA packaging and unpacking, protein-protein interactions, and intracellular delivery.

\subsection{The origin of CdSe QDs photoluminescence}

The size-dependent tunable emission of visible light is the most attractive property of CdSe QDs [5-8,19]. Photoactivated QDs relax by first intra-band transitions at $>10^{11} \mathrm{~s}^{-1}$ followed by inter-band relaxations, which include radiative carrier recombination at the band-edge, phonon-assisted non-radiative relaxations, non-radiative Auger recombination, or radiative and non-radiative recombinations at surface defects. Among these relaxation processes, radiative recombination at the band-edge accounts for the size-dependent tunable 
photoluminescence, which is mostly contributed by the electronic transition from the lowest unoccupied $5 \mathrm{~s}$ orbital of cadmium to the highest occupied $4 \mathrm{p}$ orbital of selenium [49-51]. The band edge $\left(1 \mathrm{~S}_{\mathrm{e}} 1 \mathrm{~S}_{3 / 2}\right)$ in CdSe QD shows two fourfold degeneracy due to the change of spherical-to-uniaxial symmetry, and the mixing of electron-hole exchange perturbations with the augular momenta of both electrons and holes. These states are characterized by the angular momentum $(\mathrm{J})$ values $-2,-1,0,+1,+2$ for $1 \mathrm{~S}_{3 / 2}$ and $-1,0,+1$ for $1 \mathrm{~S}_{\mathrm{e}}$ states. Among these degenerate states, $\mathrm{J}= \pm 2$ and $\mathrm{J}=0$ are spin-forbidden states. Therefore, the photoactivation of CdSe QDs close to the band edge preferentially populates $\mathrm{J}= \pm 1$ states. The deactivation of these states occurs through non-radiative relaxation to the dark exciton state followed by the radiative or non-radiative exciton recombination [50,52]. Also, the involvement of the spin-forbidden dark exciton states and surface states in the relaxation processes renders an extended photoluminescence lifetime to QDs. An alternative relaxation pathway for electrons trapped in the dark exciton state is the thermal activation into an emitting state followed by radiative or non-radiative relaxation $[50,52,53]$. Such non-radiative relaxations at the surface states contribute to the poor photoluminescence quantum efficiencies of QDs. Thus, suppression of surface defects by the preparation of semiconductor shells and surface-capping using electron donating ligands were extensively investigated as measures to improve the photoluminescence quantum efficiency of QDs.

\subsection{Physical methods for the modification of QD photoluminescence}

Physical parameters such as pressure [54], temperature [55,56], and electric [57] and magnetic fields [58] modify the photoluminescence of CdSe QDs. For example, the photoluminescence spectrum of CdSe QD blue-shifts with increasing pressure due an increase in the bandgap energy and the quantum confinement effect. Similarly, photoluminescence intensity of $\mathrm{CdSe} / \mathrm{ZnS}$ QD decreases under an applied magnetic field due to the Zeeman splitting of defect-associated energy levels [58]. On the other hand, the photoluminescence intensity of elongated $\mathrm{CdSe} / \mathrm{ZnS}$ nanoparticle enhances under an applied magnetic field due to the activation of optically inactive ground exciton states to the emissive state [59]. Under an applied electric field, the photoluminescence spectrum of CdSe QD red-shifts, which is attributed to the cancellation of components in the excited state dipole parallel to the applied electric field [57]. In general, the photoluminescence quantum yield of QD increases with decreasing temperature and vice versa [60]. The thermal quenching of photoluminescence is substantiated in terms of thermally activated non-radiative carrier recombination [60]. On the other hand, Wuister and coworkers have observed temperature antiquenching of 
photoluminescence in the case of QD capped with various ligands, which is attributed to the introduction of defects on QD surface during the phase transition of ligands [61,62]. The thermal quenching of photoluminescence intensity can be attributed to the non-radiative carrier relaxation from the thermally activated states. Photoluminescence spectral-shift associated with changes in the local temperature of QDs is another interesting property; the photoluminescence spectra of QDs shift to the red or blue upon heating or cooling, for which the degree of shift depends on the temperature. For example, continuous photoluminescence spectral blue-shift can be observed as the temperature is increased from 1.75 to $75 \mathrm{~K}$. On the other hand, red-shift is detected as the temperature is increased beyond $100 \mathrm{~K}$. The spectral red-shift associated with increase in the local temperature is attributed to the dilation of crystal lattice. Apart from the photoluminescence spectral shifts and intensity variations, photoluminescence spectral broadening that frequently accompanies heat is assigned to an increase in the scattering efficiency due to the coupling of excitons with acoustic and longitudinal optic phonons.

In addition to the above physical parameters, Föster resonance energy transfer (FRET) and surface plasmon affect the photoluminescence of QDs [63-71]. For example, CdSe/ZnS QDs placed on the surface of $\mathrm{Ag}$ nanoparticles show reduced photoluminescence intensity and lifetime due to efficient energy transfer from photoactivated QD to Ag nanoparticles (Figure 1A)[70]. On the other hand, photoluminescence intensity of QDs placed on the surface of a gold nanoparticle film show up to four-fold enhancement owing to the formation of multiexciton states [71], which is similar to the twenty-fold photoluminescence enhancement reported for heterodimers composed of CdSe/ZnS QDs and gold nanoparticles separated by DNA linkers [72]. To address the energy transfer-based photoluminescence modifications in QDs, we have recorded and analyzed the photoluminescence spectrum of QDs entrapped in polymer honeycomb-network [68] or functionalized on the surface of single walled carbon nanotube (SWCNT) [69]. Remarkable quenching of the photoluminescence intensity of QDs observed in both cases is attributed to efficient energy transfer from smaller to larger QDs close-packed in a polymer network or from QD to SWCNT in the QD-SWCNT hybrid system (Figure 1B). Nevertheless, photoinduced electron transfer from QD to Ag nanoparticles or SWCNT is not completely ruled out in these cases.

We have seen photoluminescence modulation of QD clusters as functions of heating and cooling in the temperature range 298 to $353 \mathrm{~K}$. To monitor the thermal modulation of photoluminescence, we have first recorded and analyzed the photoluminescence spectra of QD clusters, which are small (ca $30 \mathrm{~nm}$ ) aggregates of ca $3.5 \mathrm{~nm}$ CdSe QDs, dispersed in $n$ - 
butanol during both cooling and heating cycles [60]. Figure $1 \mathrm{C}$ and $\mathrm{D}$ shows the photoluminescence spectral shifts and intensity variations of QD clusters as functions of heating and cooling. The photoluminescence spectrum of QD clusters red-shifts when the temperature is increased from 298 to $353 \mathrm{~K}$, and restores to the original position upon cooling back to $298 \mathrm{~K}$. Red-shift in the photoluminescence spectra of CdSe QD superstructures reported earlier is attributed to the quantum mechanical tunneling through inter-dot barriers and the thermal activation followed by hopping above energy barriers due to excitoncoupling. In addition to the spectral shifts, the photoluminescence intensity of CdSe QD clusters increases with decrease of temperature and vice versa. These thermal modulations (spectral shifts and intensity variations) of QD photoluminescence are attributed to variations in the density of surface or interface trap states [60]. To address the variations further, a carrier relaxation model is proposed, which hypothesize two different types of surfaces or interfaces

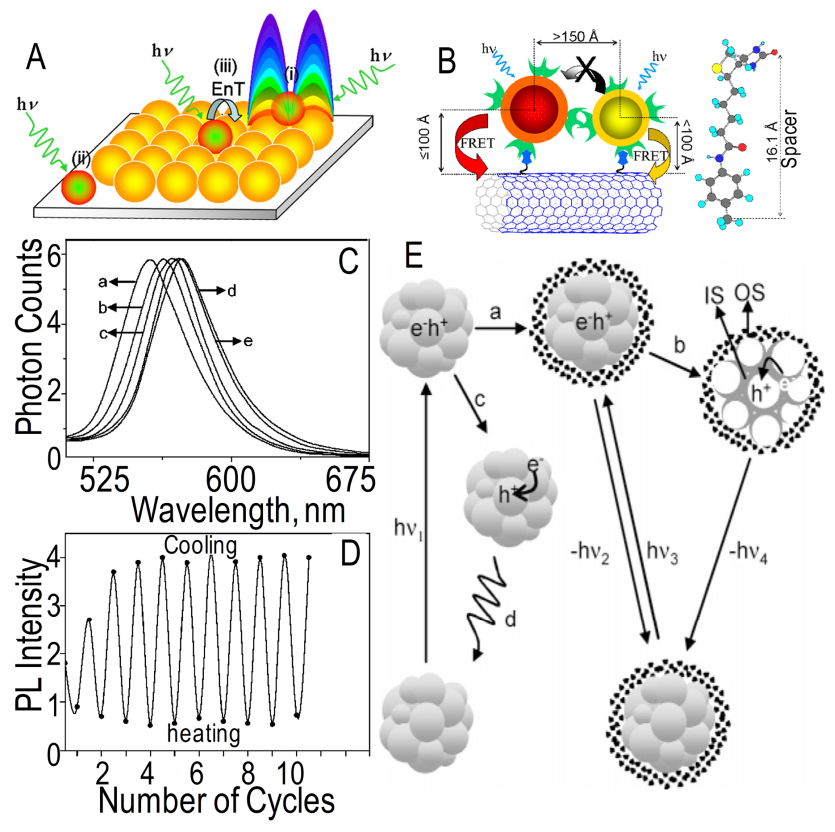

Figure 1. (A) QDs distributed on a Ag nanoparticle film: (i) a QD in a hot-spot formed between two or more Ag nanoparticles, (ii) a QD without any Ag nanoparticle in its nanoenvironment, and (iii) a QD engaged in energy transfer interactions with $\mathrm{Ag}$ nanoparticles, (B) schematic presentation of a small (yellow) and a big (red) QDs conjugated to SWCNT, (C) photoluminescence spectra of a solution of QD clusters recorded at (a) $298 \mathrm{~K}$ before heating-cooling cycles and (b-e) at $353 \mathrm{~K}$ after one to four heating-cooling cycles. Spectra b-e are normalized for intensity with respect to the spectrum before heating, (D) photoluminescence intensity variations of a QD cluster solution during heating-cooling cycles, (E) schematic presentation of relaxation processes in a photoactivated CdSe QD cluster; (a) surface passivation of photoexcited clusters by solvent molecules or dissolved oxygen, (b) thermal activation followed by the formation of 
stabilized clusters due to the inner surface (IS) trap state population and inter-dot dipoledipole interactions, (c) formation of deep trap states, and (d) non-radiative carrier recombination in deep trap states. Adapted with permission from Ref. 60, 68 and 70; copyright 2005, 2006 and 2008- ACS.

for QD clusters viz oxygen and solvent accessible outer surface (OS) and oxygen or solvent inaccessible inter-particle interface (IS). Different relaxation processes of photoactivated CdSe QD clusters are represented in Figure 1E. Our hypothesis is that the thermal modulation of photoluminescence intensity and spectral maximum of QD clusters are contributed by the relaxation of photoactivated excitons through the surface states and inter-particle interface states, carrier tunneling, and inter-dot dipole-dipole interactions.

\subsection{Chemical methods for the modification of QD photoluminescence}

Different chemical methods for the modification of QD photoluminescence are surface passivation using amines [16,19,73-78] or thiols [5,16,34,77-83], preparation of shells from large band gap inorganic materials [21,22,84-87] or carbon nanomaterials [87], and photoactivation in the presence of solvents or ligands [52,54,88-92]. Although chemical modification of QDs in general lowers the photoluminescence quantum efficiency, the enhanced solubility and biocompatibility of surface modified QDs are inevitable for their biological applications. Passivation of CdSe QD surface using alkyl amines takes place either during the quantum dots synthesis in the presence of alkyl amines [73] or by the postsynthesis exchange of ligands with amines [19,74-78]. For example, Talapin and coworkers have synthesized highly monodisperse CdSe QDs using three-component ligands such as TOPO, TOP and hexadecylamine. While this method is similar to the traditional organometallic synthesis of QD, hexadecylamine efficiently passivates the surface defects and improves the band edge photoluminescence up to 40-60\%[73]. Although the addition of alkyl amines to QDs results in the drastic quenching of photoluminescence in most cases [74-76], photoluminescence enhancement is detected in certain cases $[19,77,78]$. The addition of $n-$ butylamine to $\mathrm{CdSe}$ QD results in a drastic quenching of photoluminescence intensity, which is due to the suppression of radiative carrier recombination process by occupying the hole sites by amines [75]. On the other hand, Kamat and coworkers have seen an enhancement in the photoluminescence intensity of QDs treated with n-butylamine [74]. On the other hand, $p$ -

phenylenediamine quenches the photoluminescence intensity of QDs due to its ability to scavenge the photo-generated holes. Surface passivation of QDs using thiols is mostly a postsynthetic approach. Similar to amines, surface passivation of QDs using thiols results in the quenching [77-81] or enhancement of photoluminescence quantum efficiency $[5,82,83]$. For 
Invited Feature Article

example, the addition of either octadecanethiol or butanethiol to QD solutions results in a significant quenching of photoluminescence [79], which, as in the case of amines, is due to the blockage of photo-generated holes and hence the radiative carrier recombination process. Similarly, Wuister and coworkers have shown contradicting effects of thiols on the photoluminescence intensity of CdSe and CdTe QDs [80]; where photoluminescence quenching for CdSe QDs and enhancement for CdTe QD are observed. This anomalous behavior is accounted in terms of the difference in the valence band energies of CdSe and CdTe QDs. In another example, Hollingsworth and coworkers have shown the effect of thiolthiolate equilibrium on the photophysical properties of aqueous solutions of QDs [93]. On the other hand, Weiss and coworkers and Hong and Ha have independently observed photoluminescence enhancement and near-complete blinking suppression for QDs either embedded in polymer containing dithiothreitol [83] or supplemented with $\beta$-mercaptoethanol [34]. In both cases, the thiol moieties act as electron donors, which suppress Auger recombination and non-radiative carrier recombination. We have recently seen the quenching of photoluminescence for CdSe/ZnS QD capped with fullerene thiols [87]. Here a thick fullerene shell is prepared by the covalent tethering of a fullerene-thiol monolayer to $\mathrm{CdSe} / \mathrm{ZnS}$ quantum dot followed by the [2+2] photochemical reactions of free fullerene-thiol to the tethered monolayer. The quenching of photoluminescence intensity after preparation of the fullerene shell is accounted in terms of the combined absorption of light by the core and shell as well as photoinduced electron transfer from the QD core to fullerene shell. Inherently, we observed blinking suppression for QDs shelled with fullerene, for which the details are discussed in the following section. Despite all these reports about the covalent or noncovalent tethering of amines or thios to the surface of QDs, covalent conjugation of dihydrolipoic acid to the surface of $\mathrm{CdSe} / \mathrm{ZnS} \mathrm{QD}$, which is reported by Mattoussi and coworkers, offer a versatile platform for the chemical and bioconjugate modifications of QDs $[5,16,94]$.

The controlled photoactivation of QDs in the presence of oxygen or in certain solvents enhances the photoluminescence quantum efficiency of QDs. Buratto and coworkers have seen photoluminescence enhancement for CdSe QD passivated with water molecules [95]. Subsequently, Bard and coworkers have noticed enormous enhancement in the photoluminescence intensity of QDs saturated with oxygen and illuminated with UV light [96]. In this case, the enhancement is due the surface passivation of QDs by trace amounts of $\mathrm{CdO}$ and $\mathrm{SeO}_{2}$ formed as a result of surface oxidation. The role of oxygen on the photoluminescence enhancement is also identified by Uematsu and coworkers [97], which is 
attributed to an increase in the number of non-bonding oxygen-hole centers. Peng and coworkers and Weiss and coworkers have independently seen huge enhancements in the photoluminescence of photoactivated QDs $[92,98]$. We have seen 4-5 fold enhancements in the photoluminescence quantum efficiency of CdSe QDs dispersed in polymers or polar solvents and photoactivated above the band gap energy [90], which is associated with irreversible blue-shifts of photoluminescence spectra (Figure 2A). The enhancement of photoluminescence intensity and blue-shift of photoluminescence spectrum are due to the combined effect of surface etching and surface passivation by organic molecules and dissolved oxygen. Further, the photoluminescence is well-stabilized by dissolved polymers. The photoluminescence enhancement is contributed by a combination of the population of emitting states from the spin-forbidden dark state and chemical rearrangement of ligand molecules and the surface states (Figure 2A).

In a more recent study, we have seen a continuous drop of photoluminescence intensity for $\mathrm{CdSe} / \mathrm{ZnS}$ QDs photoactivated in the presence of 1,4-diaminobutane (DAB)[99], which is attributed to photochemical reactions of amine on the surface of photoactivated QDs and the formation QD-amine adducts of low photoluminescence quantum yields. To understand the photochemical reactions between QDs and amines, the photoluminescence intensity trajectories of single QDs were recorded and analyzed in study.

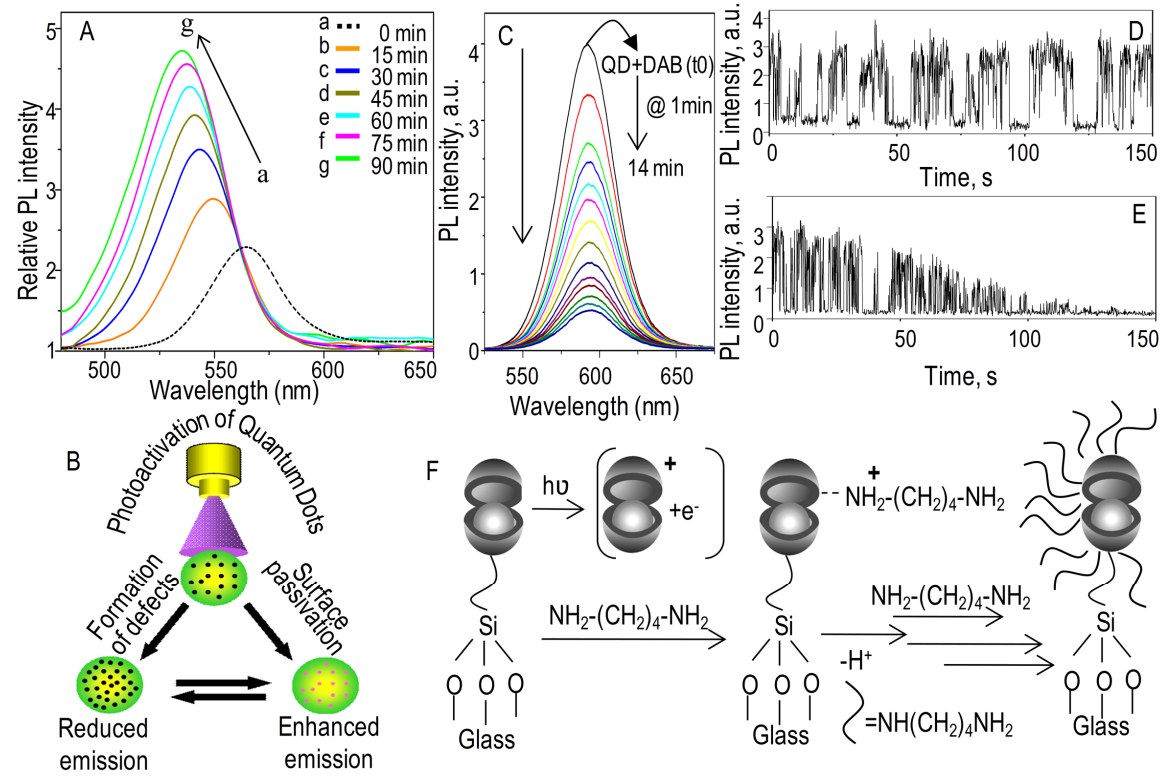

Figure 2. (A) Photoluminescence spectra recorded at different time under photoactivation of a solution of colloidal CdSe QDs in chloroform, (B) schematic representation of surface passivation and defect formation in CdSe QDs under photoactivation. (C) Photoluminescence spectra of $1 \mu \mathrm{M} \mathrm{CdSe} / \mathrm{ZnS}$ QD solution in toluene supplemented with $3 \mathrm{mM}$ DAB solution, (D and E) PL intensity trajectories of single QDs recorded under high-intensity photoactivation 
$\left(532 \mathrm{~nm}, 2.2 \mathrm{~kW} / \mathrm{cm}^{2}\right)$ : (D) without DAB, (E) with $10 \mathrm{mM}$ DAB solution, (F) schematic presentation of electron transfer from $\mathrm{DAB}$ to $\mathrm{QD}$ and the subsequent formation of $(\mathrm{DAB})_{\mathrm{n}}$ adducts. Adapted with permissions from refs. 90 and 99; copyright ACS (2007) and Co-Action (2011).

Continuous decrease in the photoluminescence intensity of QDs at ensemble and singlemolecule levels either with increase in the concentration of DAB under continuous photoactivation or time under photoirradiation for a given contraction of DAB clearly suggests photochemical reactions of DAB with photoactivated QDs. The non-digitized (gradual) decrease in the photoluminescence intensities of single quantum dots tethered on cover slips, which are supplemented with DAB and illuminated with high intensity green laser (Figure 2E) is indicative of the photochemical reactions shown in Figure 2F.

\section{Photoluminescence blinking of single QDs}

Blinking is an undesired disorder that prevents the applications of QDs in single photon devices and single-molecule bioimaging. Blinking is due to intermittent Auger ionization, which creates excess positive charge in the core. Due to the strong Coulomb interactions between subsequently activated electron and the excess positive charge, successive carrier recombinations follow non-radiative pathway by energy transfer to the excess charge, which imparts long-living OFF states in the intensity trajectories of single QDs [23,100,101]. Thus, Auger ionized QDs tend to stay in the dark state until neutralized. The power-law distribution of OFF time can be accounted in terms of an exponential distribution in the rates of electron de-trapping from an exponentially distributed trap states [101-105]. Although diffusion controlled electron transfer theory proposed by Marcus and coworkers [106-109] well-fits with the power-law statistics observed by Kuno and coworkers and Nesbitt and coworkers [101,103-105] it is often necessary to correlate blinking with dynamic nature of carrier trapping to account for the deviations of $\mathrm{ON}$ time from the power-law behavior. Such experimental and theoretical investigations in the recent past have greatly contributed to not only blinking suppression of QDs [34,67,70,85-87,110-117] but also the development of nonblinking quantum dots[118].

Non-blinking QDs are inevitable for applications such as single-photon logic devices, quantum switches, and the prolonged visualization of single molecules in biological samples. Thus, synthesis of non-blinking QDs or the suppression of blinking by post-synthesis modifications have become active research subjects [34,67,70,85-87,110-120]. The different approaches for blinking suppression include (i) removal of surface defects by capping using large band gap materials [23,85,86,115-118], thiols [34,83] and polymers [83,121], (ii) 
trapping of Auger electrons in well-defined electron traps [87,110,122], plasmon-assisted energy transfer [70,123], thermal activation [124], oxygen depletion [125], electron transfer to and from inorganic nanoparticles and organic molecules [87,104,110,122,126,127], and photoactivation[128,129]. Details of a few methods for blinking suppression are discussed below.

\subsection{Modification of blinking by surface passivation}

Blinking of QDs can be suppressed by surface passivation using large bang gap materials $[22,23,85,86]$, thiols $[34,83]$ or polymers [83,121]. Hollingsworth and coworkers have reported blinking suppression of single CdSe QD by varying the thickness of $\mathrm{CdS}$ or $\mathrm{ZnS}$ shell [85], which is similar to the near complete blinking suppression of $\mathrm{CdS}$ shelled $\mathrm{CdSe}$ QD by preparing shells from CdS [83]. Here, the blinking is suppressed due to the minimal lattice mismatch between the core and shell and the low density of charge carrier traps. Similarly, Hohng and Ha have seen near-complete blinking suppression of CdSe/ZnS QDs by thiol passivation [34]. Blinking suppression is also accomplished by surface passivation using ATPase [130] or polymer impregnated with dithiothreitol [83]. Although the exact mechanism of blinking suppression is still under investigation, electron transfer, soft quantum confinement, and enhanced radiative relaxation due to reduction in the density of electron traps are suggested in the above examples.

\subsection{Modification of blinking using well-defined electron traps}

As discussed in the previous section, Auger ionized QDs continue to stay in the OFF state until neutralized. Thus, a well-defined electron trap in the vicinity of a QD is expected to trap the Auger electron and successively neutralize the Auger ionized QD by back-electron transfer. For example, we have recently investigated the blinking suppression of single $\mathrm{CdSe} / \mathrm{ZnS}$ QDs supplemented with $\mathrm{TiO}_{2}$ nanoparticles (Figure 3A and B) [110]. Here, $\mathrm{CdSe} / \mathrm{ZnS}$ QDs are covalently tethered on the surface of glass cover slips, and the photoluminescence intensity trajectories of the same single QDs are recorded before and after the addition of colloidal $\mathrm{TiO}_{2}$ nanoparticles. Interestingly, the blinking of single QDs is suppressed as soon as a $\mathrm{TiO}_{2}$ nanoparticle solution is injected. According to our hypothesis, blinking is suppressed as a result of the trapping of Auger electrons in the conduction band of $\mathrm{TiO}_{2}$ nanoparticles followed by back-electron transfer to the Auger ionized QD. In other words, blinking is suppressed by increasing the rate of neutralization of Auger ionized QD via introducing well-defined electron traps in the vicinity of QD. Here the transferred electrons 
are not conducted away as the surface of QD is sparsely doped by $\mathrm{TiO}_{2}$ nanoparticles. On the other hand, Jin and Lian have seen aggravation of blinking in the case of QDs embedded in $\mathrm{TiO}_{2}$ nanoparticle films, which is evidenced by a decrease in the ON time and increase in the OFF time due to efficient electron transfer from QD to $\mathrm{TiO}_{2}$ nanoparticles in the film [122]. Similarly, changes in the QD blinking behavior induced by electron acceptors such as $\mathrm{C}_{60}$ were reported recently by us [87] and Lian and coworkers [131]. In our work, we have prepared a well-defined fullerene shell around CdSe/ZnS QDs by the tethering of a monolayer of fullerene thiol to the $\mathrm{ZnS}$ shell, which is followed by the photochemical [2+2] cycloaddition reactions of free fullerene-thiol to the tethered monolayer as seen in Figure $3 \mathrm{C}$ [87]. The photoluminescence intensity trajectories of QDs in such fullerene-shelled supramolecular nanoparticles show an increase in the occurrence of ON and OFF events when compared with pristine QDs. In other words, both ON and OFF durations were shortened after the preparation of a fullerene shell. An increase in the number of OFF events or shortening of $\mathrm{ON}$ time is attributed to an increase in the rate of electron transfer from QD core to the fullerene shell, which was confirmed by recording the anion radical spectrum of fullerene (Figure 3D). An increase in the number of ON events or shortening of OFF time is attributed to an increase in the rate of neutralization of Auger ionized QDs by the backelectron transfer from the fullerene shell.

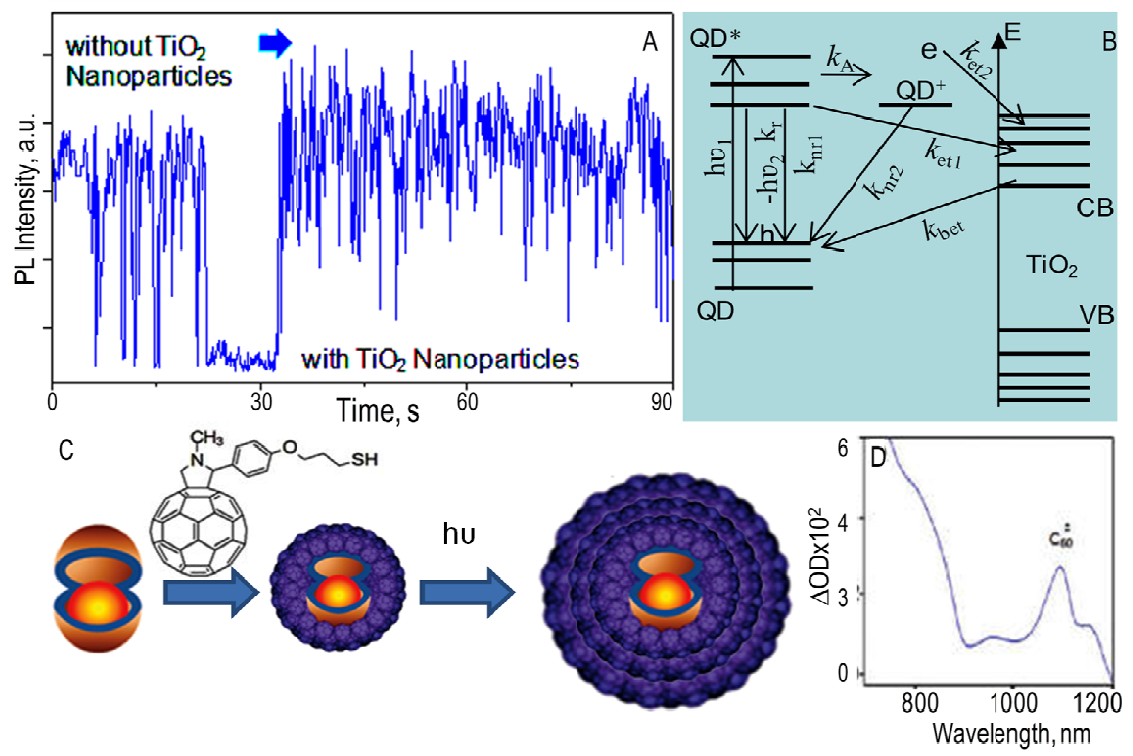

Figure 3. (A) Photoluminescence intensity trajectory of a single CdSe/ZnS QD before and after the addition of $\mathrm{TiO}_{2}$ nanoparticles, (B) schematic presentation of photoactivation and relaxation in a $\mathrm{CdSe} / \mathrm{ZnS}$ QD in the presence of $\mathrm{TiO}_{2}$ nanoparticles, (C) photofabrication of fullerene-shelled supramolecular 
nanoparticles, (D) transient absorption spectrum of a fullerene-shelled QD sample. Adapted with permission from Ref. [87, 110]; copyright 2012 and 2010, ACS.

\subsection{Modification of blinking by plasmonic coupling method}

Noble metal nanoenvironment induces fluctuations, enhancement, and quenching of QD photoluminescence intensity at ensemble and single-molecule levels [67,70,115,132-134]. For example, Kanemitsu and coworkers have detected photoluminescence quenching and enhancement of single QDs placed on gold-coated surfaces. Here, the quenching or enhancement depends on the strength of the plasmon field contributed by the surface roughness [67]. In general, delocalization of Auger electrons with localized surface plasmon resonance of metal nanostructures is known to suppress blinking of QDs. We have seen plasmon assisted blinking suppression of QDs placed on the surface of Ag nanoparticles [70]. Here, blinking suppression is associated with reduction in the photoluminescence intensity and shortening of photoluminescence lifetime. We hypothesize energy/electron transfer process from photoactivated QD to Ag nanoparticles, which competes with various relaxation pathways including Auger recombination, is involved in the blinking suppression. Subsequently Tang and coworkers [123] have seen plasmon-mediated blinking suppression for QDs placed on silver nanoprisms in a thin poly methyl methacrylate (PMMA) layer.

\section{Biological applications of QDs}

Although organic dyes are extensively used as fluorescent biolabels for many decades, a variety of other materials including endogenous fluorescent proteins [135], upconversion nanoparticles [136,137], lanthanide chelates [138], carbon nanoparticles [139], silicon nanoparticles [140], quantum clusters [141] and QDs [5,6,8,142] have recently emerged as new generation fluorescent tags for biolabeling and imaging. Due to large number of reports about biological applications of QDs and other nanomaterials, a comprehensive review of the field is not attempted here. Instead, we review our recent work about biological applications of CdSe/ZnS QDs and related reports in the literature. Unique optical properties of QDs such as absorption of light in the UV-Vis-NIR window, narrow emission bandwidth, large one- and multi-photon absorption cross-sections, high photoluminescence quantum yield, and exceptional photostability make them ideal for bioimaging. Furthermore, the straightforward and reproducible synthetic protocols, large surface area, flexible surface chemistry, compatibility in the aqueous phase, chemical- and photo- stabilities under physiological 
Invited Feature Article

conditions, and commercial availability in the ready-to-conjugate forms increase the popularity of QDs among biologists $[5,8,48]$.

\subsection{QD for Förster resonance energy transfer (FRET)}

Organic dyes, owing to their small size and commercial availability in different colors and reactive forms, are extensively employed as both donors and acceptors of energy in the construction of FRET pairs for biosensing and bioimaging. The broad absorption band, exceptionally high photostability and narrow emission bands of QDs are certainly promising properties to replace energy donor organic dyes from FRET pairs $[26,36,38,63,67,143,144]$. For example, Clapp and coworkers have demonstrated the use of water-soluble Cys-capped $\mathrm{CdSe} / \mathrm{ZnS}$ QDs as energy donors in the analysis of the dissociation of DNA/polymer polyplexes on exposure to chloroquine [145] In another study, Leong and coworkers have exploited the two-step FRET approach in a QD-based FRET pair system to analyze noninvasive DNA condensation [146]. Similarly, Turberfield and coworkers have exploited QDbased FRET systems for the monitoring of DNA cage delivery in mammalian cells [147]. In another example, Medintz and coworkers have shown FRET-based biosensing of $\beta$ cyclodextrin-QSY9 using the adduct of QD and Escherichia coli maltose-binding protein (MBP) [63]. Similarly, Zhang and coworkers have reported QD-based multiplex detection of HIV-1 and HIV-2 using QD 605 -Alexa Fluor 488 or -Alexa Fluor 647 dye FRET pair. The detection principle in this case is based on the interactions of QD-based nanosensors fabricated using biotinylated oligonucleotides with AlexaFour-labeled oligonucleotides, which are gap gene of HIV-1 and the env gene of HIV-2 [148]. Recently, we have constructed FRET-pairs involving CdSe/ZnS QD as energy donors and applied them for analyzing some selected biomolecular processes such as the condensation and decondensation of plasmid DNA [149,150], single-molecule analysis of ATPase reaction [151] and the detection of single-molecule activation of epidermal growth factor (EGF) receptors in living cells [152]. For example, by measuring FRET from CdSe/ZnS QD to Cy5, we have successfully evaluated the condensation of plasmid DNA using protamine and the successive decondensation of the protamine-DNA complex using heparan sulfate and glutathione [150]. Here we introduced FRET recovery after acceptor photobleaching (FRET-RAP) method for the first time, by which highly photostable QDs were used for energy transfer-based knocking out any undesired Cy5 acceptor labeled proximal to the donors [150]. In another example, the stepwise ATPase reaction was evaluated by the prolonged monitoring of single-molecule FRET from QD-labeled myosin Va to Cy3-labeled ATP [151]. Similarly, the prolonged 
visualization of single-molecule FRET and photoluminescence in QD- and Cy5- labeled EGF/EGF receptor complexes enabled us to identify the reversible dimerization of EGF receptors in the early stage of cell signaling [152].

\subsubsection{FRET-based detection of DNA condensation and decondensation}

The condensation and decondensation of DNA can be effectively evaluated from the efficiencies of intermolecular or intramolecular FRET. In the former case, DNA molecules are labeled with either acceptors or donors of energy and the condensing agents with the counterpart of FRET pair. On the other hand, both donors and acceptors labeled on DNA in the later case can provide sensitive changes to the intramolecular FRET efficiency. However, labeling of a definite number of donors and acceptors at desired locations in DNA or any other system but without any FRET before DNA condensation or bringing about the desired change is tedious. To overcome this issue, we have introduced the FRET-RAP method, in which FRET-mediated knockout of undesired acceptors allows us to retain adequate numbers of donors and acceptors spatially separated without any FRET [150]. Precisely, biotinylated pcDNA3.1 or pUC18DNA molecules are first randomly labeled with countable (ca 10) $\mathrm{CdSe} / \mathrm{ZnS}$ QDs as highly photostable energy donors and a large number of AlexaFlour 594 or cy5 dyes as photolabile energy acceptors. This random labeling provided us with efficient intrinsic FRET in the as-labeled DNA, which is due to the large number of acceptors in the proximity of acceptors. However, under the selective excitation of QDs, efficient energy transfer to those dye molecules present within the Förster distance of QDs resulted in the

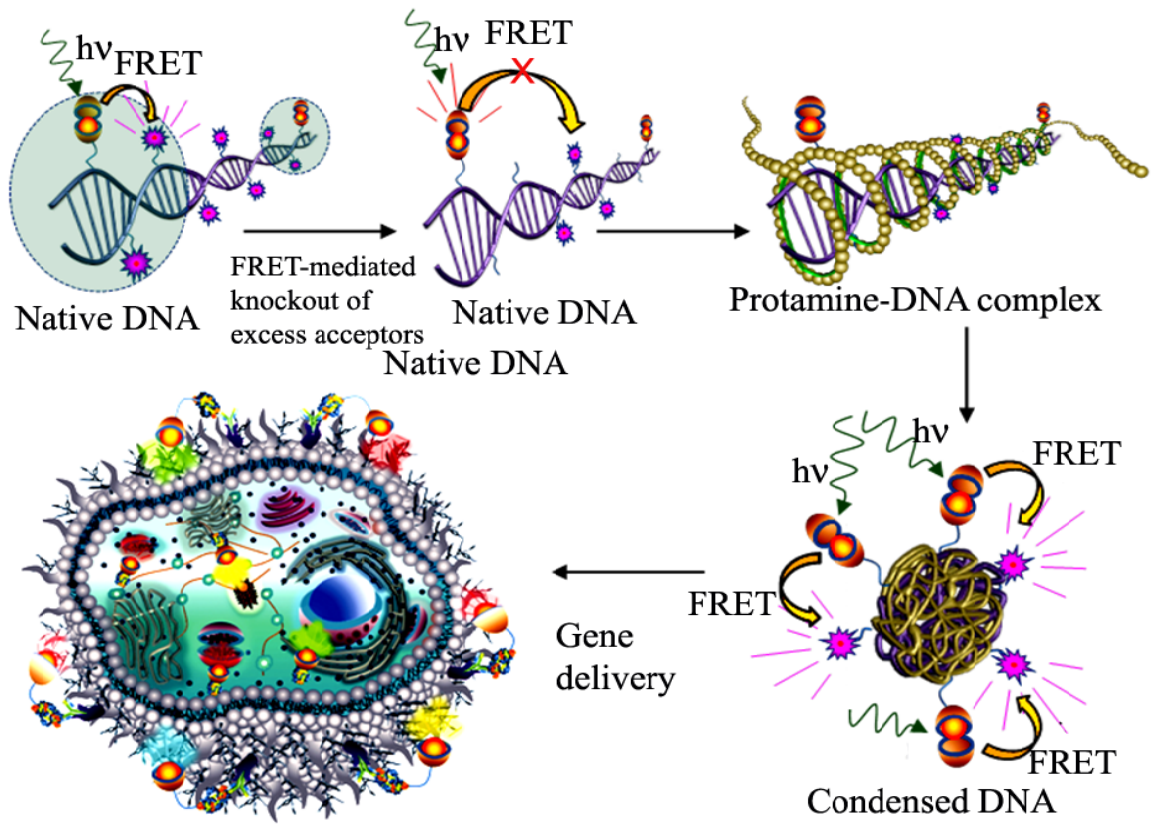


Figure 4. (A) Hypothesis about FRET-RAP method for the detection of condensation and decondensation of DNA. Adapted with permission from ref. 150. Copyright 2012, ACS.

photodecomposition of undesired acceptors; whereas, a large number of acceptors located beyond the Förster distance were kept intact. Thus, the intrinsic FRET in the as-labeled DNA is removed. Those acceptors retained on DNA after FRET-mediated photobleaching of undesired acceptors provided us with efficient intramolecular FRET during the condensation of DNA using protamine. Also, the FRET efficiency was substantially lowered during the decondensation of pDNA-protamine complex using trisma base or a mixture of heparan sulfate and glutathione (Figure 4). FRET from $\mathrm{CdSe} / \mathrm{ZnS}$ QDs to rhodamine dye is also utilized for the monitoring of intracellular DNA decondensation and gene delivery [149].

To evaluate any adverse effect of QDs on genetic materials, we have first analyzed the morphology of QD-labeled pDNA molecules. Surprisingly, we observed photosensitized strand breakage and nucleobase damage in pDNA [153]. To obtain detailed information about such photosensitized breakage and damage of DNA, solutions of QD-conjugated pDNA molecules are exposed to green or blue laser and the samples were analyzed by AFM imaging, gel electrophoresis and the assay of reactive oxygen intermediates (ROI) (Figure 5). DNA fragments seen in AFM and gel images suggested strand breakage. The photosensitized damage of DNA by QDs was further examined using base excision repair enzymes such as formamidopyrimidine glycosylase (Fpg) and endonuclease III (Endo III). The nucleobase

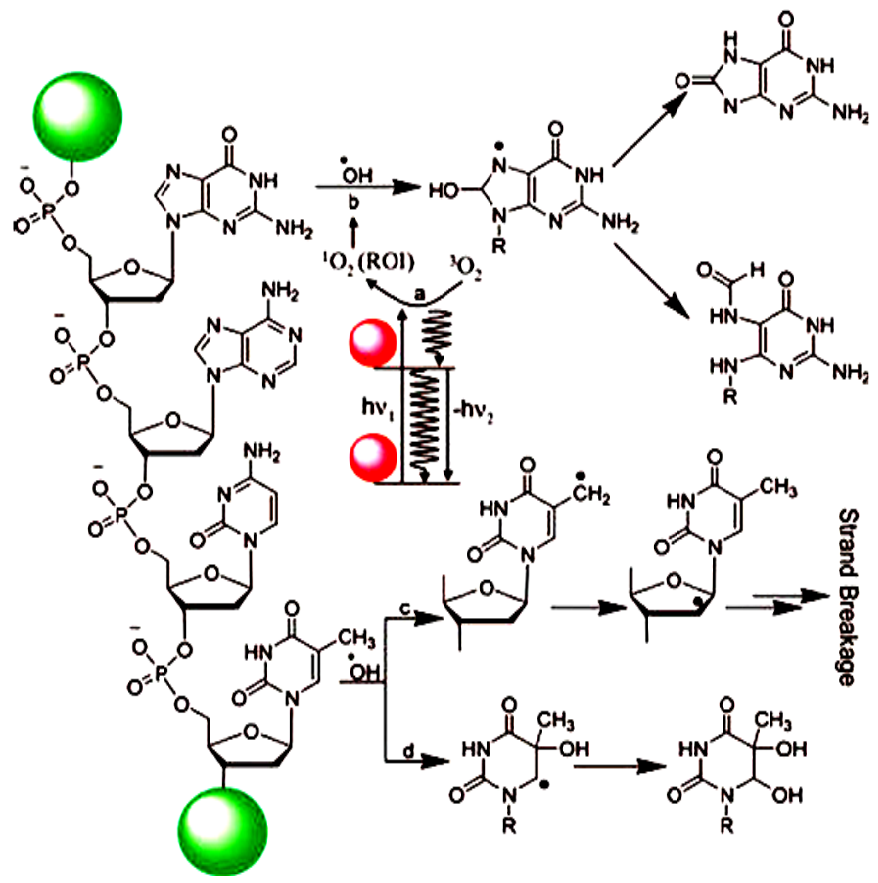


Figure 5. Schematic presentation of (a) photosensitized production of ROI by QDs, (b, d) nucleobases damages by ROI, and (c) DNA strand breakage due to hydrogen abstraction by ROI. Adapted with permission from ref. 154. Copyright 2008, ACS.

damage of QD-conjugated DNA is attributed to the reactions of DNA with ROI such as singlet oxygen and hydroxyl radical produced by photoactivated QDs, which is further evaluated by the nitroblue tetrazolium (NBT) assay. Although QDs are widely used in bioimaging, their toxicity is not yet completely rationalized. In addition to the photosensitized toxicity induced by ROI, air oxidation and surface etching of heavy metal-based QDs such as $\mathrm{CdS}, \mathrm{CdSe}, \mathrm{CdTe}, \mathrm{PbS}, \mathrm{PbSe}, \mathrm{PbTe}$, etc. results in the release of toxic levels of metal ions, which in turn impair genomic DNA and other vital biomolecules in cells [154,155]. Although the release of heavy metal ions from QD can be minimized by surface protection using shells from $\mathrm{ZnS}$, silica and polymers, gradual etching of the shells by enzymatic reactions in biological systems and physico-chemical effects in the environment needs adequate attention for long term exposure.

\subsubsection{Single-molecule ATPase reaction}

Single-molecule FRET measurement is a powerful method for the detailed characterization of biochemical and biophysical dynamics in the nanometer regime. Enzymatic reactions of molecular motors, protein-protein and protein-DNA interactions, and protein folding are examples of such dynamics. Recently, Yanagida and coworkers have shown the potentials of green fluorescent $\mathrm{CdSe} / \mathrm{ZnS}$ QD as an efficient energy donor for the sensitive detection of single-molecule ATP hydrolysis by myosin V [151]. Here, we labeled the recombinant human myosin Va with QD near to the ATP binding site. For the labeling, a mutant myosin was prepared by the substitution of lysine-270 with cysteine. Subsequently, maleimidefunctionalized QD was conjugated to the cysteine reside without affecting the enzymatic activity of myosin. The QD-conjugated enzyme molecules were immobilized on a cover glass, which was subsequently assembled into a flow chamber. Single-molecule enzymatic reactions of Cy5-conjugated ATP were detected as a function of FRET from QD to Cy5. Efficient FRET from highly photostable QDs to Cy5 enabled us to not only detect the reaction with high signal to noise ratio in the presence of high $(>100 \mathrm{nM})$ concentrations of Cy5-ATP but also follow the single-molecule enzymatic reactions for an extended period of time. 


\subsubsection{Single-molecule detection of the dimerization of EGF receptors}

Cell signaling by G-protein coupled receptors in the membrane are initiated by the binding of ligands to the extracellular domain, which is followed by changes in the conformations of extracellular and cytoplasmic domains and signal transduction [156,157]. To evaluate early events in the cell signaling by EGF receptor, we have recorded and analyzed the photoluminescence trajectories and images of EGF receptor single molecules labeled using QD-EGF and Cy5-anti-EGFR antibody conjugates [152]. Here, biotinylated EGF was labeled using streptavidin-functionalized $\mathrm{CdSe} / \mathrm{ZnS}$ QD $\left(\operatorname{Em} \lambda_{\max }\right.$ ca $\left.605 \mathrm{~nm}\right)$ and biotinylated antiEGFR antibody was labeled using streptavidin functionalized Cy5. First, EGF receptors in human ovarian epidermoid carcinoma (A431) cells were activated by the incubation of cells with EGF-QD conjugates. The dimerization of EGF receptors in the cell membrane was evaluated by obtaining single-molecule fluorescence (Figure 6A and B) and FRET images, and single-molecule photoluminescence intensity trajectories and photoluminescence lifetimes of QD-only labeled or QD and Cy5 labeled dimers of EGF receptors. Fluorescence intensity trajectories and FRET images of predimer (without EGF), heterodimer (with one EGF per dimer) and signaling dimer (two EGF per dimer) forms suggested reversible association and dissociation of EGF receptors during the early stage of cell signaling.

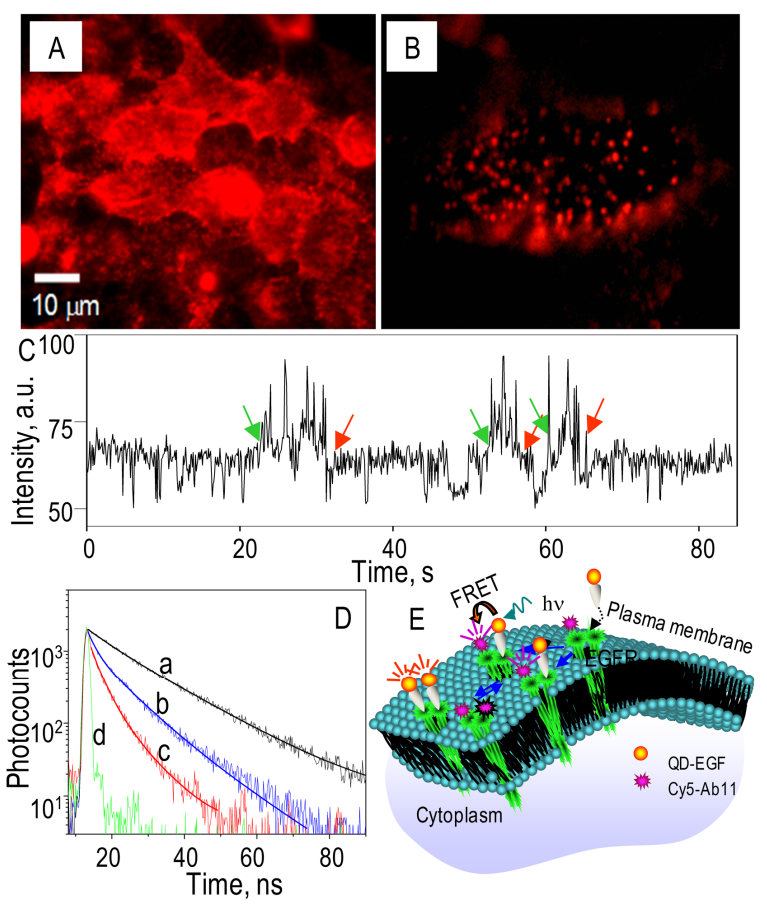

Figure 6. (A and B) Fluorescence images of living A431 cells activated with (A) $2 \mathrm{nM}$ and (B) $0.5 \mathrm{nM}$ QD-EGF conjugates, (C) single-molecule fluorescence intensity trajectory of a heterodimer that undergoes reversible dimerization with other heterodimers. The arrows indicate the formation (green) and dissociation (red) of homodimers, (D) fluorescence decay 
profiles of QD and Cy5 in an A431 cell: (a) decay of QD in QD-EGF only labeled cells, (b) decay of QD in 1:1 QD and Cy5 labeled cells, (c) decay of Cy5 in 1:1 QD-EGF and Cy5-anti EGF receptor antibody-labeled cells, and (d) instrument response function. (E) Schematic presentation of reversible propagation of EGFR activation in cell membrane. Adapted with permission from ref. 153. Copyright 2010, Wiley VCH.

\subsection{Quantum dots for cell imaging}

In the recent past, QD conjugated to a variety of biomolecules such as antibodies, peptides, proteins, nucleic acid, aptamers and liposomes have become common in cell labeling and imaging both in vitro and in vivo [5,6,8,48,141,158-168]. The nature of functional group introduced and the type of biomolecules recruited on the surface of QD depend on individual labeling application. For example, streptavidin, biotin, primary amine, thiol, maleimide, succinimide and carboxylic acid are common functionalities on the surface of CdSe/ZnS QDs for the tethering of proteins, hormones, antibodies, small ligands, peptides, aptamers, etc. $[8,16]$. Nevertheless, there are reports about non-specific labeling of cells using QD without any specific functional group/biomolecules. However, bioengineered QDs facilitate targeted labeling of specific organelles, imaging of extracellular receptors, detection of membrane dynamics, delivery of genes and drugs, and photodynamic therapy of cancer cells $[15,16]$. Such targeted labeling of cells using RGD peptides, immunoliposomes, antibodies, aptamers, EGF, Tat peptide, folic acid, etc. is recently reviewed [8]. We have successfully delivered $\mathrm{CdSe} / \mathrm{ZnS}$ QDs in living cells using allatostatin I (AST), which is a neuropeptide present in crustaceans. Incubation of mouse embryonic fibroblast cell (3T3) or A431 cells with ASTconjugated QDs results in an efficient intracellular transport of the conjugate(Figure 7A and B) $[169,170]$. Here we selected AST due to the functional and sequence similarities of its receptor in crustaceans to mammalian G-protein-coupled galanin receptors. However, our studies involving galanin, galanin antagonist, allatostatin mutant or heparan sulfate rule out galanin receptor-mediated or charge-based intracellular delivery of the conjugate [169]. On the other hand, investigations involving the inhibition of the regulatory enzyme phosphoinositide 3-kinase (PI3K) with wortmannin or immunostaining of clathrin proteins using QD-labeled anti-clathrin antibody (Figure 7C) suggest clathrin-mediated endocytosis of the conjugate as shown in Figure 7D. Despite the efficient intracellular transport of QDs using this insect-derived peptide, which is cost-effective when compared with many biomolecules, the exact extracellular machinery involved in the binding of AST in human cell membrane remains mysterious. 

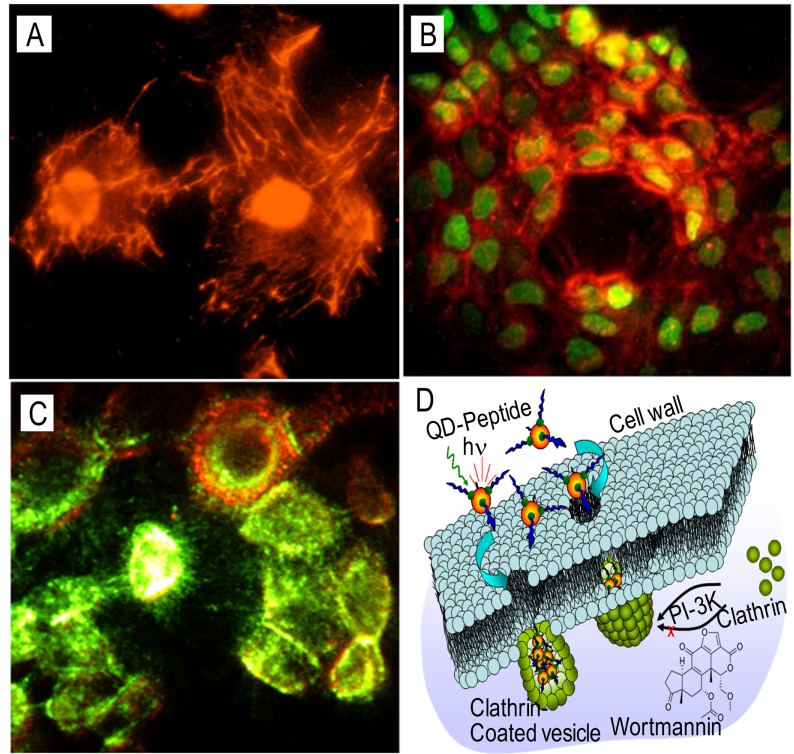

Figure 7. Fluorescence image of the $3 \mathrm{~T} 3$ cells (A) and A431 cells (B) incubated with QD-AST conjugates (green staining in the nucleus is due to Syto 21 dye), (C) fluorescence image of A431 cells treated with QD (green)-conjugated heavy chain of anti-clathrin antibody and QD (red)-conjugated AST, and (D) schematic presentation of clathrin-mediated endocytosis of QD-AST conjugates. Adapted with permission from ref. 169 and 170. Copyright 2007 and 2009, ACS.

\section{Summary and outlook}

Systematic advancements in the semiconductor quantum dot research area, which follow the theoretical insight into the size-dependent energy levels of quantum confined nanomaterials made by Louis Brus, have brought to us unique nanomaterials capable of transforming our daily life. With the introduction of unique and simplified methods for the synthesis and surface modification, quantum dots have infiltrated into various aspects of device technology and biology- from light emitting diode (LED) screens and solar cells to bioanalytical platforms and nanomedicine. Further, the systematic investigations and optimization of charge carrier dynamic as functions of the materials composition and structures of the core, shell and surface ligands, the optical properties of quantum dots are fully-blown to provide inimitable platforms for bioanalysis, bioimaging and the construction of optical devices. Also, surface modification of quantum dots using different inorganic and organic materials and molecules followed by surface bioengineering using proteins, peptides or nucleic acids enables us to not only strengthen an interface among materials science, chemistry and biology but also resolve many challenging problems in biology and biomedical science. Nonetheless, photoluminescence blinking due to Auger ionization and toxicity due to 
Invited Feature Article

heavy metal contents are two major unsolved issues in the quantum dot field. Photoluminescence blinking of quantum dots, which hampers potential single-molecule applications such as single photon logic devices and single-molecule bioanalysis, is partially addressed in recent studies that involve surface modification and electron transfer. While heavy metal-based quantum dots such as $\mathrm{CdS}, \mathrm{CdSe}, \mathrm{CdTe}, \mathrm{PbS}, \mathrm{PbSe}, \mathrm{PbS}, \mathrm{PbTe}, \mathrm{HgS}$, $\mathrm{HgSe}$ and $\mathrm{HgTe}$ should find more promising in vitro applications, novel non-toxic quantum dots are necessary for in vivo imaging and nanomedicine applications.

\section{Acknowledgment}

VB thank Japan Science and Technology Agency for support under the Precursory Research for Embryonic Science and Technology (PRESTO) program and Japan Society for the Promotion of Science (JSPS) for Grant-in-Aid for Scientific Research (Wakate-B). ES acknowledges JSPS postdoctoral fellowship.

\section{References}

1. L. Dykman, N. Khlebtsov, Chem. Soc. Rev. 41 (2012) 2256.

2. $\quad$ P.K. Jain, X. Huang, I.H. El-Sayed, M.A. El-Sayed, Acc. Chem. Res. 41 (2008) 1578.

3. W.I. Choi, A. Sahu, Y.H. Kim, G. Tae, Ann. Biomed. Eng. 40 (2011) 534.

4. $\quad$ S. Lal, S.E. Clare, N.J. Halas, Acc. Chem. Res. 41 (2008) 1842.

5. I.L. Medintz, H.T. Uyeda, E.R. Goldman, H. Mattoussi, Nat. Mater. 4 (2005) 435.

6. V. Biju, T. Itoh, A. Anas, A. Sujith, M. Ishikawa, Anal. Bioanal. Chem. 391 (2008) 2469.

7. R.C. Somers, M.G. Bawendi, D.G. Nocera, Chem. Soc. Rev. 36 (2007) 579.

8. V. Biju, T. Itoh, M. Ishikawa, Chem. Soc. Rev. 39 (2010) 3031.

9. L. Cheng, K. Yang, Y. Li, J. Chen, C. Wang, M. Shao, S.-T. Lee, Z. Liu, Angew. Chem. Int. Ed. 50 (2011) 7385.

10. L. Cheng, K. Yang, Y. Li, X. Zeng, M. Shao, S.-T. Lee, Z. Liu, Biomaterials 33 (2012) 2215.

11. B. Dong, S. Xu, J. Sun, S. Bi, D. Li, X. Bai, Y. Wang, L. Wang, H. Song, J. Mater. Chem. 21 (2011) 6193.

12. J.-W. Kim, E.I. Galanzha, E.V. Shashkov, H.-M. Moon, V.P. Zharov, Nat. Nanotechnol. 4 (2009) 688.

13. F. Zhou, S. Wu, B. Wu, W.R. Chen, D. Xing, Small 7 (2011) 2727.

14. Z. Liu, K. Chen, C. Davis, S. Sherlock, Q. Cao, X. Chen, H. Dai, Cancer Res. 68 (2008) 6652.

15. E. S. Shibu, M. Hamada, N. Murase, V. Biju, J. Photochem. Photobiol. C: Photochem. Rev. 15 (2013) 53.

16. V. Biju, Chem. Soc. Rev. 42 (2013) DOI:10.1039/C3CS60273G.

17. Y. Yin, A.P. Alivisatos, Nature 437 (2005) 664.

18. L.E. Brus, J. Chem. Phys. 80 (1984) 4403.

19. C.B. Murray, D.J. Norris, M.G. Bawendi, J. Am. Chem. Soc. 115 (1993) 8706.

20. T. Vossmeyer, L. Katsikas, M. Gienig, I.G. Popovic, K. Diesner, A. Chemseddine, A. Eychmiiller, H. Weller, J. Phys. Chem. 98 (1994) 7665. 
21. M.A. Hines, P. Guyot-Sionnest, J. Phys. Chem. 100 (1996) 468.

22. B.O. Dabbousi, J. Rodriguez-Viejo, F.V. Mikulec, J.R. Heine, H. Mattoussi, R. Ober, K.F. Jensen, M.G. Bawendi, J. Phys. Chem. 101 (1997) 9463.

23. M. Nirmal, B.O. Dabbousi, M.G. Bawendi, J.J. Macklin, J.K. Trautman, T.D. Harris, L.E. Brus, Nature 383 (1996) 802.

24. A.L. Efros, M. Rosen, M. Kuno, M Nirmal, D.J. Norris, M.G. Bawendi, Phys. Rev. B 54 (1996) 4843.

25. D.J. Norris, M.G. Bawendi, J. Chem. Phys. 103 (1995) 5260.

26. M.P. Bruchez, M. Moronne, P. Gin, S. Weiss, A.P. Alivisatos, Science 281 (1998) 2013.

27. W.C. Chan, S. Nie, Science 281 (1998) 2016.

28. Z.A. Peng, X. Peng, J. Am. Chem. Soc. 123 (2001) 183.

29. Z.A. Peng, X. Peng, J. Am. Chem. Soc. 124 (2002) 3343.

30. A.L. Rogach, A. Kornowski, M. Gao, A. Eychmüller, H. Weller, J. Phys. Chem. B 103 (1999) 3065.

31. J. Zhu, O. Palchik, S. Chen, A. Gedanken, J. Phys. Chem. B 104 (2000) 7344.

32. A. Mandal, J. Nakayama, N. Tamai, V. Biju, M. Ishikawa, J. Phys. Chem. B 111 (2007) 12765.

33. G.P. Mitchell, C.A. Mirkin, R.L. Letsinger, J. Am. Chem. Soc. 121 (1999) 8122.

34. S. Hohng, T. Ha, J. Am. Chem. Soc. 126 (2004) 1324.

35. H.S. Choi, W. Liu, P. Misra, E. Tanaka, J.P. Zimmer, B. I. Ipe, M.G. Bawendi, J.V. Frangioni, Nat. Biotechnol. 25 (2007) 1165.

36. H. Mattoussi, J.M. Mauro, E.R. Goldman, G.P. Anderson, V.C. Sundar, F.V. Mikulec, M.G. Bawendi, J. Am. Chem. Soc. 122 (2000) 12142.

37. J.B. Delehanty, I.L. Medintz, T. Pons, F.M. Brunel, P.E. Dawson, H. Mattoussi, Bioconjugate Chem. 17 (2006) 920.

38. E.R. Goldman, E.D. Balighian, H. Mattoussi, M.K. Kuno, J.M. Mauro, P.T. Tran, G.P. Anderson, J. Am. Chem. Soc. 124 (2002) 6378.

39. H.T. Uyeda, I.L. Medintz, J.K. Jaiswal, S.M. Simon, H. Mattoussi, J. Am. Chem. Soc. 127 (2005) 3870.

40. D. Gerion, F. Pinaud, S.C. Williams, W.J. Parak, D. Zanchet, S. Weiss, A.P. Alivisatos, J. Phys. Chem. B 105 (2001) 8861.

41. X. Wu, H. Liu, J. Liu, K.N. Haley, J.A. Treadway, J.P. Larson, N. Ge, F. Peale, M.P. Bruchez, Nat. Biotechnol. 21 (2002) 41.

42. T. Pellegrino, L. Manna, S. Kudera, T. Liedl, D. Koktysh, A.L. Rogach, S. Keller, J. Rädler, G. Natile, W.J. Parak, Nano Lett. 4 (2004) 703.

43. F. Osaki, T. Kanamori, S. Sando, T. Sera, Y. Aoyama, J. Am. Chem. Soc. 126 (2004) 6520.

44. X. Gao, Y. Cui, R.M. Levenson, L.W.K. Chung, S. Nie, Nat. Biotechnol. 22 (2004) 969.

45. L.C. Mattheakis, J.M. Dias, Y.-J. Choi, J. Gong, M.P. Bruchez, J. Liu, E. Wang, Anal. Biochem. 327 (2004) 200.

46. B. Ballou, B.C. Lagerholm, L.A. Ernst, M.P. Bruchez, A.S. Waggoner, Bioconjugate Chem. 15 (2004) 79.

47. H. Duan, S. Nie, J. Am. Chem. Soc. 129 (2007) 3333.

48. V. Biju, S. Mundayoor, R.V. Omkumar, A. Anas, M. Ishikawa, Biotechnol. Adv. 28 (2010) 199.

49. M. Nirmal, L.E. Brus, Acc. Chem. Res. 32 (1999) 407.

50. D.F. Underwood, T. Kippeny, S.J. Rosenthal, J. Phys. Chem. B 105 (2001) 436.

51. V.I. Klimov, D.W. McBranch, C.A. Leatherdale, M.G. Bawendi, Phys. Rev. B 60 
(1999) 13740 .

52. M. Jones, J. Nedeljkovic, R.J. Ellingson, A.J. Nozik, G. Rumbles, J. Phys. Chem. B 107 (2003) 11346.

53. M.G. Bawendi, P.J. Carroll, W.L. Wilson, L.E. Brus, J. Chem. Phys. 96 (1992) 946.

54. B.S. Kim, M.A. Islam, L.E. Brus, I.P. Herman, J. Appl. Phys. 89 (2001) 8127.

55. M. Nirmal, C.B. Murray, M.G. Bawendi, Phys. Rev. B 50 (1994) 2293.

56. A. Al Salman, A. Tortschanoff, M.B. Mohamed, D. Tonti, F. van Mourik, M. Chergui, Appl. Phys. Lett. 90 (2007) 093104.

57. S.A. Empedocles, M.G. Bawendi, Science 278 (1997) 2114.

58. M. Di Vece, B. Kolaric, K. Baert, G. Schweitzer, M. Obradovic, R.A.L. Vallée, P. Lievens, K. Clays, Nanotechnology 20 (2009) 135203.

59. Y. Louyer, L. Biadala, J.B. Trebbia, M.J. Fernée, P. Tamarat, B. Lounis, Nano Lett. 11 (2011) 4370.

60. V. Biju, Y. Makita, A. Sonoda, H. Yokoyama, Y. Baba, M. Ishikawa, J. Phys. Chem. B 109 (2005) 13899.

61. S.F. Wuister, A. van Houselt, C. de Mello Donegá, D. Vanmaekelbergh, A. Meijerink, Angew. Chem. Int. Ed. 43 (2004) 3029.

62. S.F. Wuister, C. de Mello Donegá, A. Meijerink, J. Am. Chem. Soc. 126 (2004) 10397.

63. I.L. Medintz, A.R. Clapp, H. Mattoussi, E.R. Goldman, B. Fisher, J.M. Mauro, Nat. Mater. 2 (2003) 630.

64. I.L. Medintz, H. Mattoussi, Phys. Chem. Chem. Phys. 11 (2009) 17.

65. A.R. Clapp, I.L. Medintz, J.M. Mauro, B.R. Fisher, M.G. Bawendi, H. Mattoussi, J. Am. Chem. Soc. 126 (2004) 301.

66. C.-Y. Zhang, H.-C. Yeh, M.T. Kuroki, T.-H. Wang, Nat. Mater. 4 (2005) 826.

67. Y. Ito, K. Matsuda, Y. Kanemitsu, Phys. Rev. B 75 (2007) 033309.

68. R. Kanemoto, A. Anas, Y. Matsumoto, R. Ueji, T. Itoh, Y. Baba, S. Nakanishi, M. Ishikawa, V. Biju, J. Phys. Chem. C 112 (2008) 8184.

69. V. Biju, T. Itoh, Y. Baba, M. Ishikawa, J. Phys. Chem. B 110 (2006) 26068.

70. Y. Matsumoto, R. Kanemoto, T. Itoh, S. Nakanishi, M. Ishikawa, V. Biju, J. Phys. Chem. C 112 (2008) 1345.

71. J. Kim, J. Lee, K. Kyhm, Appl. Phys. Lett. 99 (2011) 213112.

72. M.M. Maye, O. Gang, M. Cotlet, Chem. Commun. 46 (2010) 6111.

73. D.V. Talapin, A.L. Rogach, A. Kornowski, M. Haase, H. Weller, Nano Lett. 1 (2001) 207.

74. S.N. Sharma, Z.S. Pillai, P.V. Kamat, J. Phys. Chem. B 107 (2003) 10088.

75. C.F. Landes, C. Burda, M. Braun, M.A. El-Sayed, J. Phys. Chem. B 105 (2001) 2981.

76. C.F. Landes, M. Braun, M.A. El-Sayed, J. Phys. Chem. B 105 (2001) 10554.

77. C. Bullen, P. Mulvaney, Langmuir 22 (2006) 3007.

78. G. Kalyuzhny, R.W. Murray, J. Phys. Chem. B 109 (2005) 7012.

79. A.M. Munro, I. Jen-LaPlante, M.S. Ng, D.S. Ginger, J. Phys. Chem. C 111 (2007) 6220.

80. S.F. Wuister, C. de Mello Donegá, A. Meijerink, J. Phys. Chem. B 108 (2004) 17393.

81. R. Koole, P. Schapotschnikow, C. de Mello Donegá, T.J.H. Vlugt, A. Meijerink, ACS Nano 2 (2008) 1703.

82. D.A.R. Barkhouse, A.G. Pattantyus-Abraham, L. Levina, E.H. Sargent, ACS Nano 2 (2008) 2356.

83. J. Antelman, Y. Ebenstein, T. Dertinger, X. Michalet, S. Weiss, J. Phys. Chem. C 113 (2009) 11541.

84. P. Reiss, M. Protiere, L. Li, Small, 2009, 5, 154.

85. Y. Chen, J. Vela, H. Htoon, J.L. Casson, D.J. Werder, D.A. Bussian, V.I. Klimov, J.A. 
Hollingsworth, J. Am. Chem. Soc. 130 (2008) 5026.

86. B. Mahler, P. Spinicelli, S. Buil, X. Quelin, J.-P. Hermier, B. Dubertret, Nat. Mater. 7 (2008) 659.

87. E.S. Shibu, A. Sonoda, Z. Tao, Q. Feng, A. Furube, S. Masuo, L. Wang, N. Tamai, M. Ishikawa, V. Biju, ACS Nano 6 (2012) 1601.

88. A. Mandal, N. Tamai, Chem. Phys. Lett. 507 (2011) 248.

89. Y. Wang, Z. Tang, M.A. Correa-Duarte, I. Pastoriza-Santos, M. Giersig, N.A. Kotov, L.M. Liz-Marzán, J. Phys. Chem. B 108 (2004) 15461.

90. V. Biju, R. Kanemoto, Y. Matsumoto, S. Ishii, S. Nakanishi, T. Itoh, Y. Baba, M. Ishikawa, J. Phys. Chem. C 111 (2007) 7924.

91. A.Y. Nazzal, X. Wang, L. Qu, W. Yu, Y. Wang, X. Peng, M. Xiao, J. Phys. Chem. B 108 (2004) 5507.

92. X. Wang, L. Qu, J. Zhang, X. Peng, M. Xiao, Nano Lett. 2003, 3, 1103.

93. S. Jeong, M. Achermann, J. Nanda, S. Ivanov, V.I. Klimov, J.A. Hollingsworth, J. Am. Chem. Soc. 127 (2005) 10126.

94. A.R. Clapp, E. R. Goldman, H. Mattoussi, Nat. Protocols 1 (2006) 1258.

95. S.R. Cordero, P.J. Carson, R.A. Estabrook, G.F. Strouse, S.K. Buratto, J. Phys. Chem. B 104 (2000) 12137.

96. N. Myung, Y. Bae, A.J. Bard, Nano Lett. 3 (2003) 747.

97. T. Uematsu, S. Maenosono, Y. Yamaguchi, Appl. Phys. Lett. 89 (2006) 031910.

98. J.M. Tsay, S. Doose, F. Pinaud, S. Weiss, J. Phys. Chem. B 109 (2005) 1669.

99. M. Hamada, E.S. Shibu, T. Itoh, M.S. Kiran, S. Nakanishi, M. Ishikawa, V. Biju, Nano Reviews 2 (2011) 6366.

100. A.L. Efros, M. Rosen, Phys. Rev. Lett. 78 (1997) 1110.

101. M. Kuno, D.P. Fromm, H.F. Hamann, A. Gallagher, D.J. Nesbitt, J. Chem. Phys. 112 (2000) 3117.

102. R. Verberk, A. van Oijen, M. Orrit, Phys. Rev. B 66 (2002) 233202.

103. M. Kuno, D. Fromm, S. Johnson, A. Gallagher, D.J. Nesbitt, Phys. Rev. B 67 (2003) 125304.

104. V. Fomenko, D.J. Nesbitt, Nano Lett. 8 (2008) 287.

105. J.J. Peterson, D.J. Nesbitt, Nano Lett. 9 (2009) 338.

106. P. Frantsuzov, R.A. Marcus, Phys. Rev. B 72 (2005) 155321.

107. J. Tang, R.A. Marcus, J. Chem. Phys. 123 (2005) 054704.

108. J. Tang, R.A. Marcus, Phys. Rev. Lett. 95 (2005) 107401.

109. M. Pelton, G. Smith, N.F. Scherer, R.A. Marcus, Proc. Natl. Acad. Sci. USA 104 (2007) 14249.

110. M. Hamada, S. Nakanishi, T. Itoh, M. Ishikawa, V. Biju, ACS Nano 4 (2010) 4445.

111. K. Shimizu, W. Woo, B. Fisher, H. Eisler, M.G. Bawendi, Phys. Rev. Lett. 89 (2002) 117401.

112. Y. Fu, J. Zhang, J.R. Lakowicz, Chem. Phys. Lett. 447 (2007) 96.

113. C.T. Yuan, P. Yu, J. Tang, Appl. Phys. Lett. 94 (2009) 243108.

114. S. Masuo, H. Naiki, S. Machida, A. Itaya, Appl. Phys. Lett. 95 (2009) 193106.

115. C. Heyes, A. Kobitski, V. Breus, G. Nienhaus, Phys. Rev. B 75 (2007) 125431.

116. P. Spinicelli, S. Buil, X. Quélin, B. Mahler, B. Dubertret, J.P. Hermier, Phys. Rev. Lett. $102(2009) 136801$.

117. F. García-Santamaría, Y. Chen, J. Vela, R.D. Schaller, J.A. Hollingsworth, V.I. Klimov, Nano Lett. 9 (2009) 3482.

118. X. Wang, X. Ren, K. Kahen, M.A. Hahn, M. Rajeswaran, S. Maccagnano-Zacher, J. Silcox, G.E. Cragg, A.L. Efros, T.D. Krauss, Nature 459 (2009) 686.

119. V. Biju, Y. Makita, T. Nagase, Y. Yamaoka, H. Yokoyama, Y. Baba, M. Ishikawa, J. 
Phys. Chem. B 109 (2005) 14350.

120. H. He, H. Qian, C. Dong, K. Wang, J. Ren, Angew. Chem. Int. Ed. 45 (2006) 7588.

121. H.C. Ko, C.T. Yuan, S.H. Lin, J. Tang, Appl. Phys. Lett. 96 (2010) 012104.

122. S. Jin, T. Lian, Nano Lett. 9 (2009) 2448.

123. C.T. Yuan, P. Yu, H.C. Ko, J. Huang, J. Tang, ACS Nano 3 (2009) 3051.

124. K. Shimizu, R. Neuhauser, C. Leatherdale, S. Empedocles, W. Woo, M.G. Bawendi, Phys. Rev. B 63 (2001) 205316.

125. F. Koberling, A. Mews, T. Basche, Adv. Mater. (2001) 672.

126. S.-C. Cui, T. Tachikawa, M. Fujitsuka, T. Majima, J. Phys. Chem. C 112 (2008) 19625.

127. S.-C. Cui, T. Tachikawa, M. Fujitsuka, T. Majima, J. Phys. Chem. C 114 (2010) 1217.

128. K.L. Knappenberger, D.B. Wong, Y.E. Romanyuk, S.R. Leone, Nano Lett. 7 (2007) 3869.

129. K. Goushi, T. Yamada, A. Otomo, J. Phys. Chem. C 113 (2009) 20161.

130. V. Rombach-Riegraf, P. Oswald, R. Bienert, J. Petersen, M.P. Domingo, J. Pardo, P. Gräber, E.M. Galvez, Biochem. Biophys. Res. Commun. 430, (2012) 260.

131. N. Song, H. Zhu, S. Jin, W. Zhang, T. Lian, ACS Nano 5 (2011) 613.

132. J. Zhang, Y.-H. Ye, X. Wang, P. Rochon, M. Xiao, Phys. Rev. B 72 (2005) 201306.

133. O. Kulakovich, N. Strekal, A. Yaroshevich, S. Maskevich, S. Gaponenko, I. Nabiev, U. Woggon, M. Artemyev, Nano Lett. 2 (2002) 1449.

134. F.M. Huang, F. Festy, D. Richards, Appl. Phys. Lett. 87 (2005) 183101.

135. N.C. Shaner, P.A. Steinbach, R.Y. Tsien, Nat. Meth. 2 (2005) 905.

136. F. Chen, S. Zhang, W. Bu, Y. Chen, Q. Xiao, J. Liu, H. Xing, L. Zhou, W. Peng, J. Shi, Chem. Eur. J. (2012) 7082.

137. S. Gai, P. Yang, C. Li, W. Wang, Y. Dai, N. Niu, J. Lin, Adv. Funct. Mater. 20 (2010) 1166.

138. B. Wang, J. Hai, Q. Wang, T. Li, Z. Yang, Angew. Chem. Int. Ed. 50 (2011) 3063.

139. Y.-P. Sun, B. Zhou, Y. Lin, W. Wang, K.A.S. Fernando, P. Pathak, M.J. Meziani, B.A. Harruff, X. Wang, H. Wang, P.G. Luo, H. Yang, M.E. Kose, B. Chen, L.M. Veca, S.-Y. Xie, J. Am. Chem. Soc. 128 (2006) 7756.

140. J.H. Warner, A. Hoshino, K. Yamamoto, R.D. Tilley, Angew. Chem. Int. Ed. 117 (2005) 4626.

141. E.S. Shibu, S. Sugino, K. Ono, H. Saito, A. Nishioka, Y. Yamamura, M. Sawada, Y. Nosaka, V. Biju, Angew. Chem. Int. Ed. 52 (2013) 10559.

142. S.J. Rosenthal, J.C. Chang, O. Kovtun, J.R. McBride, I.D. Tomlinson, Chemistry \& Biology 18 (2011) 10.

143. D. Zhou, J.D. Piper, C. Abell, D. Klenerman, D.-J. Kang, L. Ying, Chem. Commun. (2005) 4807.

144. E.R. Goldman, G.P. Anderson, P.T. Tran, H. Mattoussi, P.T. Charles, J.M. Mauro, Anal. Chem. 74 (2002) 841.

145. B. Zhang, Y. Zhang, S.K. Mallapragada, A.R. Clapp, ACS Nano 5 (2011) 129.

146. H.H. Chen, Y.-P. Ho, X. Jiang, H.-Q. Mao, T.-H. Wang, K.W. Leong, Nano Today 4 (2009) 125.

147. A.S. Walsh, H. Yin, C.M. Erben, M.J.A. Wood, A.J. Turberfield, ACS Nano 5 (2011) 5427.

148. C.-Y. Zhang, J. Hu, Anal. Chem. 82 (2010) 1921.

149. S.M. Shaheen, H. Akita, A. Yamashita, R. Katoono, N. Yui, V. Biju, M. Ishikawa, H. Harashima, Nucleic Acids Res. 39 (2011) e48.

150. V. Biju, A. Anas, H. Akita, E.S. Shibu, T. Itoh, H. Harashima, M. Ishikawa, ACS Nano 6 (2012) 3776.

151. M. Sugawa, S. Nishikawa, A.H. Iwane, V. Biju, T. Yanagida, Small 6 (2010) 346. 
152. N. Kawashima, K. Nakayama, K. Itoh, T. Itoh, M. Ishikawa, V. Biju, Chem. Eur. J. 16 (2010) 1186.

153. A. Anas, H. Akita, H. Harashima, T. Itoh, M. Ishikawa, V. Biju, J. Phys. Chem. B 112 (2008) 10005.

154. A.M. Derfus, W.C.W. Chan, S.N. Bhatia, Nano Lett. 4 (2004) 11.

155. P. Jones, S. Sugino, S. Yamamura, F. Lacy, V. Biju, Nanoscale 5 (2013) 9511.

156. P. Klein, D. Mattoon, M.A. Lemmon, J. Schlessinger, Proc. Natl. Acad. Sci USA 101 (2004) 929.

157. B.S. Khakh, R.A. North, Nature 442 (2006) 527.

158. A.M. Smith, H. Duan, A.M. Mohs, S. Nie, Adv. Drug Deliv. Rev. 60 (2008) 1226.

159. T. Jamieson, R. Bakhshi, D. Petrova, R. Pocock, M. Imani, A.M. Seifalian, Biomaterials 28 (2007) 4717.

160. S. Kim, Y.T. Lim, E.G. Soltesz, A.M. De Grand, J. Lee, A. Nakayama, J.A. Parker, T. Mihaljevic, R.G. Laurence, D.M. Dor, L.H. Cohn, M.G. Bawendi, J.V. Frangioni, Nat. Biotechnol. 22 (2003) 93.

161. W. Cai, D.-W. Shin, K. Chen, O. Gheysens, Q. Cao, S.X. Wang, S.S. Gambhir, X. Chen, Nano Lett. 6 (2006) 669.

162. M.E. Åkerman, W.C.W. Chan, P. Laakkonen, S.N. Bhatia, E. Ruoslahti, Proc. Natl. Acad. Sci. USA 99 (2002) 12617.

163. B. Dubertret, P. Skourides, D. J. Norris, V. Noireaux, A. H. Brivanlou, A. Libchaber, Science 298 (2002) 1759.

164. D.R. Larson, W.R. Zipfel, R.M. Williams, S.W. Clark, M.P. Bruchez, F.W. Wise, W.W. Webb, Science 300 (2003) 1434.

165. X. Michalet, F.F. Pinaud, L.A. Bentolila, J.M. Tsay, S. Doose, J.J. Li, G. Sundaresan, A.M. Wu, S.S. Gambhir, S. Weiss, Science 307 (2005) 538.

166. J. Gao, B. Xu, Nano Today 4 (2009) 37.

167. W.C. Chan, D.J. Maxwell, X. Gao, R.E. Bailey, M. Han, S. Nie, Curr. Opin. Biotechnol. 13 (2002) 40.

168. E. S. Shibu, K. Ono, S. Sugino, A. Nishioka, A. Yasuda, Y. Shigeri, S. Wakida, M. Sawada, V. Biju, ACS Nano 7 (2013) DOI:10.1021/nn4043699.

169. A. Anas, T. Okuda, N. Kawashima, K. Nakayama, T. Itoh, M. Ishikawa, V. Biju, ACS Nano 3 (2009) 2419.

170. V. Biju, D. Muraleedharan, K. Nakayama, Y. Shinohara, T. Itoh, Y. Baba, M. Ishikawa, Langmuir 23 (2007) 10254. 